\title{
A PWM Current Source Based DC Transmission System for Multiple Wind Turbine Interfacing
}

\author{
Yuanye Xia, Khaled H. Ahmed, Senior Member, IEEE, and B. W. Williams
}

\begin{abstract}
A PWM current source wind energy conversion system based on a parallel configuration for HVDC application is proposed. A comparison between the parallel and series configurations for current source based systems is investigated, which shows the merits of the proposed system. A new control technique for the PWM current source inverter is proposed. It can effectively control the average DC link voltage with a feed forward loop, while independently controlling reactive power according to grid code requirements. The system simulation confirms the performance of the proposed system with no interaction between wind turbine modules and satisfying performance with grid integration. Practical implementation further verifies the proposed inverter control. Finally, a brief comparison between conventional line-commutated converter based systems and the proposed PWM current source converter based system is presented.
\end{abstract}

Index Terms-Wind energy, HVDC, Current source converter, Grid integration

\section{INTRODUCTION}

$\mathrm{I}^{\mathrm{N}}$ N 2012, worldwide wind energy capacity reached $283 \mathrm{GW}$ with an increase in global wind power market by more than $10 \%$ compared to 2011 [1]. Wind energy capacity is increasing at a steady pace. Based on the European Wind Energy Association's estimation up to 2030, the wind energy capacity will probably reach $1,778 \mathrm{GW}$, which is $15.1 \%$ of global electricity demand for 2030. While in ambitious scenarios, the capacity may reach $2,342 \mathrm{GW}$, almost $21.8 \%$ of global electricity demand [2].

Different wind energy conversion systems have been developed to achieve such a goal. Among them, the variable speed system with a permanent magnet synchronous generator (PMSG) and full rated power electronic converter shows many benefits over other systems and is becoming more attractive. However the DC transmission and grid integration for such a configuration remains a challenge.

Manuscript received Jan. 31, 2014; revised Jun 6, 2014. Accepted for publication August 6, 2014.

Copyright (c) 2009 IEEE. Personal use of this material is permitted. However, permission to use this material for any other purposes must be obtained from the IEEE by sending a request to pubs-permissions@ieee.org.

Yuanye Xia and B.W.Williams are with the Department of Electronic and Electrical Engineering, University of Strathclyde, Glasgow, G11XW, U.K.

Khaled H. Ahmed is with the Electrical Engineering Department, Faculty of Engineering, Alexandria University, Alexandria 21544, Egypt. (e-mail: xiayuanye@gmail.com,

b.w.williams@eee.strath.ac.uk )
A current source line commutated converter (LCC), which uses thyristors for the main switching devices, has an established, proven track record over five decades in high voltage direct current (HVDC) transmission. Its main advantages are low conversion losses and high overload capacity. Such a system has been investigated for wind energy conversion systems. In $[3,4]$ the authors focus on the reactive power and harmonic compensation technique for the LCC in wind energy applications. The LCC was further improved in [5-7] using a 12-pulse scheme with better harmonic performance, without a reactive power compensator. Instead of single wind turbine interfacing, an LCC based system has been investigated to directly interface a DC network based wind farm [8], where each wind turbine is individually controlled by an LCC, series connected and integrated to a common DC bus. The advantage is that the DC link voltage can accumulate without an additional transformer or a step up converter. Being line-commutated, its switching frequency is restricted by the AC network power frequency. Also, it has the following disadvantages: require large passive filters to mitigate low order frequency harmonics, slow dynamic response, dependent active and reactive power control, large footprint, and susceptibility to AC network disturbance [9].

A pulse width modulation (PWM) voltage source converter (VSC) based DC transmission system, using self-commutated devices, such as the insulated gate bipolar transistor (IGBT) as a main switching device, is a developing direction of present and future progress for wind energy integration. It has significant performance benefits and can mitigate most of the shortcomings of LCC based systems. It allows the use of high frequency pulse width modulation (with a switching frequency of order the 1 to $2 \mathrm{kHz}$ ), resulting in fast dynamics response, small AC filters, independent control of active and reactive power, and grid fault ride through capability, although at a cost of higher switching losses. Conventional two-level VSC has been investigated for wind energy application [10, 11]. The wind turbine is individually controlled by a full rated VSC and parallel connected to a common DC link. The DC link is integrated to the grid and controlled by a VSC. Multilevel voltage source converters were developed to address limitations of two-level converters in high voltage applications. A common voltage source multilevel converter is neutral-point clamped [12]. It generates lower harmonic distortion, requires approximately half the switching frequency of that of a two-level converter to generate output voltage with the same quality, lower voltage stress across a single switch, and higher power rating [13]. However, the main disadvantages include more switches, more complex control, and the requirement for 
a neutral-point or clamping capacitor balancing mechanism [12]. For both two-level and multilevel VSCs, a large decoupling capacitor is required at the DC side to maintain constant DC link voltage, which is critical for high-power high-voltage applications [14]. Electrolytic capacitors for this purpose are heavy, bulky, expensive, and voltage limited. The DC link capacitor deteriorates with time, which represents a major system lifetime limiting factor [15]. Additionally, the DC link capacitor make the system vulnerable to short circuit faults.

Besides the two power transmission and grid integration systems introduced, a current source converter (CSC) based system using self-commutated devices is also attracting interest. As self-commutated devices are employed, the problems of the LCC based system can be addressed, and performance similar to that of a VSC based system can be achieved. In addition, as the DC link capacitor is replaced by a relatively large inductor, the system is inherently robust to both DC and AC short circuit faults [16]. Furthermore, as the current is defined, the system controller is simpler when injecting power into an AC network which is a voltage source. Active and reactive power control of the PWM CSC in wind energy applications has not been extensively investigated in the literature, the configuration and control strategy of an associated wind farm also needs further study. In [17], a back-to-back CSC based system is used to interface a single wind turbine to the grid. The DC link current is controlled to a minimum to reduce system losses. The generator power value is fed forward to the inverter controller to ensure system stability and dynamic performance. However, the main problem is that communication is required between the generator and the inverter grid side.

This paper presents a PWM current source wind energy conversion system based on a parallel configuration HVDC for multiple wind turbine interfacing. The proposed controller adjusts the average DC link voltage with a feed forward loop while independently controlling reactive power according to the grid code. The paper is organized in eight sections. Section I introduces three different power transmission and grid integration systems with their advantages and disadvantages. In Section II, the possible HVDC connections for wind energy conversion system are discussed. In Section III, a new PWM CSC based wind energy conversion system is discussed. A new control method for this system is proposed in Section IV. The simulation and experimental results of the proposed control system are assessed and evaluated in sections V and VI, respectively. Finally, a comparison between the proposed PWM CSC based system and the conventional LCC based system is presented.

\section{Series/PARALlel CSC BASEd HVDC CONNECTION}

There are two possible wind energy conversion based HVDC grid connections for CSC based systems, series or parallel, as shown in Fig 1 parts a and $b$, respectively.

In [18], a series connected generator side converter configuration, as shown in Fig. 1, is proposed based on the CSC. The advantage is that the high DC link voltage is achieved without transformers. In this system the DC link current is controlled by the current source inverter (CSI) according to a look-up table to minimize losses when the DC link power is low. The authors [19] further develop this concept by adapting multiple series connected grid side CSIs. Thus the power and voltage ratings for individual CSIs decrease.

However, the series configuration suffers from the following disadvantages.

i. If one of the modules fails, a current bypass path must be established. Therefore extra switches may be required. Also, if many converters fail, given finite boosting of the grid connect CSI, the remaining converters will need to increase their output voltage, beyond their normal operating voltage.

ii. It is difficult to incorporate or remove a series connected wind turbine module for integration or maintenance if the system is already in operation.

iii. Conduction losses increase as all modules are in series connection, hence all modules carry rated current.

iv. Output voltage sharing of the generator side converters is an issue, as their output voltages are not balanced [20] (experience voltage depends on output power).

v. Converters are not at ground potential.

In order to mitigate these drawbacks, the novel configuration shown in Fig. 1b, which is similar to a VSI based DC network, is proposed. The wind turbine modules are parallel connected, while the CSI delivers the power into the grid and controls the DC link. To the authors' knowledge, such a system configuration has not been investigated. It has the following advantages. First, output voltage balancing is not required for parallel connected current source rectifiers (CSRs), as the CSR large output reactance decouples the CSRs. Second, the cable inductance and CSR output inductor can be utilized by the CSI, eliminating extra bulky and expensive passive components. A novel control technique for the grid connected CSI is proposed, superficially similar to that used in traditional HVDC, to properly control such a WECS with high performance and stability during all network operating conditions.

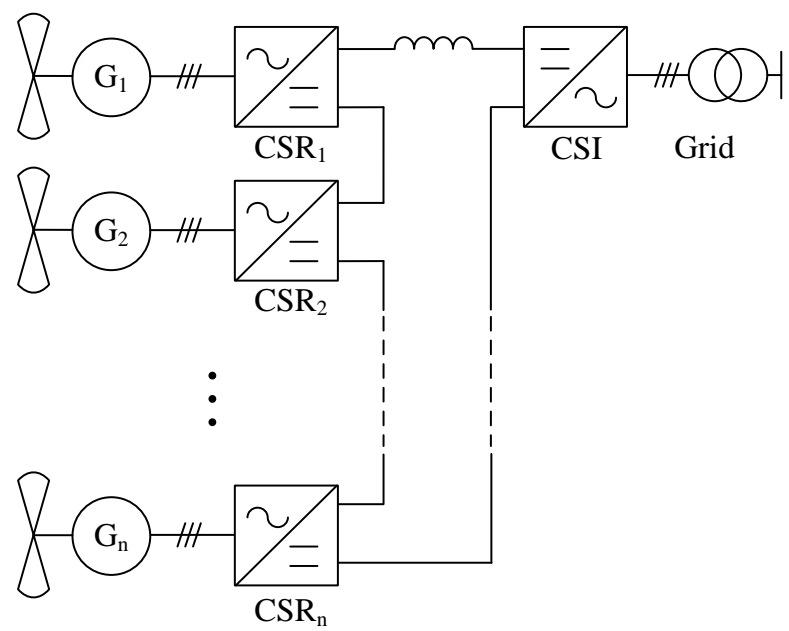

(a) 


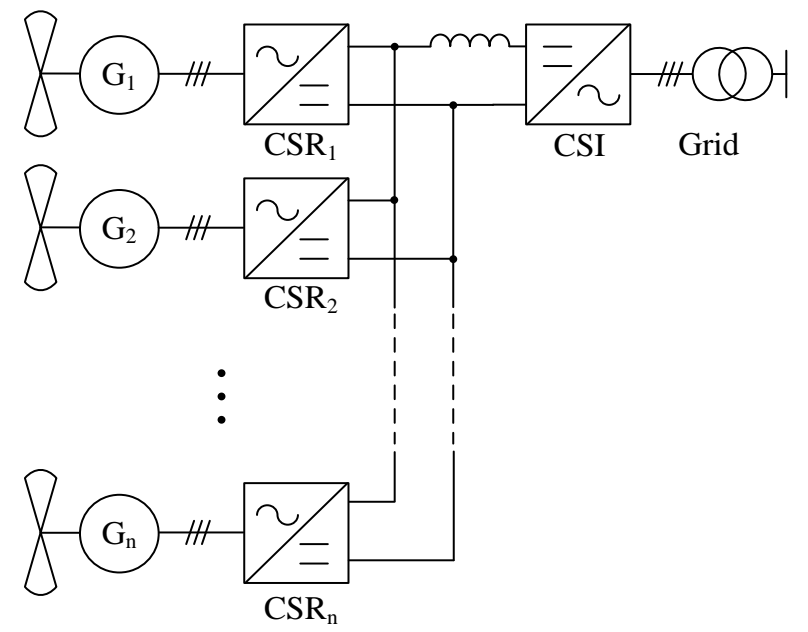

(b)

Fig. 1 CSC based wind farm (a) serial connected wind turbines, and (b) parallel connected wind turbines.

\section{SYSTEM CONFIGURATION}

The proposed CSC based system configuration shown in Fig. $1 \mathrm{~b}$ is introduced in detail in this section. A PMSG is used as the generator due to its higher efficiency and reliability compared with electrically excited synchronous generators [21]. The generator side CSR controls its associated wind turbine to track its maximum power point (MPP). In the proposed WECS, the generator three phase $\mathrm{AC}$ voltage is converted to a $\mathrm{DC}$ voltage by a diode rectifier because of its simplicity, low cost, and reliability compared to fully controlled AC/DC converters [9]. A DC/DC converter is used to control the wind turbine and boost the output to a suitable DC link voltage. For grid connection reasons, especially for HVDC transmission systems, a DC/DC converter with a high voltage step-up ratio is required. In this case, a full bridge DC/DC converter with electrical isolation [22] is employed. It has the following advantages compared to a boost converter:

- Can step up the input voltage to a high value;

- The generator and DC link are electrically isolated;

- Magnetic core utilization is increased;

- The DC/DC converter output is a current source, thus suitable for parallel connection to the proposed current source inverter based system.

The CSR with a diode rectifier and full bridge DC/DC converter is shown in Fig. 2a. A conventional three-phase, full-wave bridge current source converter (CSC) could also be used as the CSR. The CSI using insulated gate bipolar transistor (IGBT) series connected with a diode is shown in Fig. 2b. It includes a DC-link inductor and an AC side second-order CL output filter. The resistor at the AC side represents line parasitic resistance.

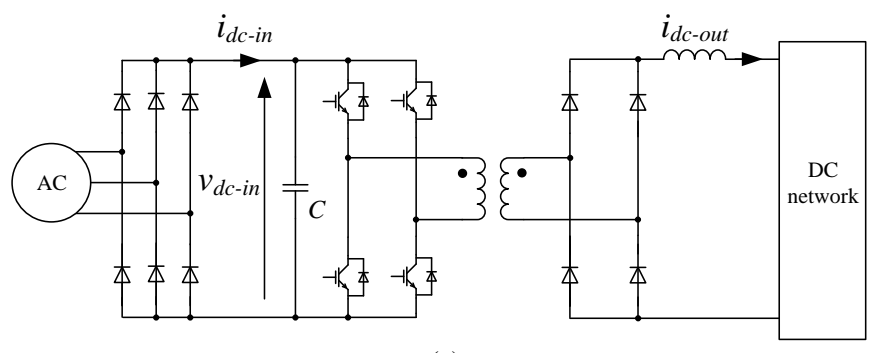

(a)

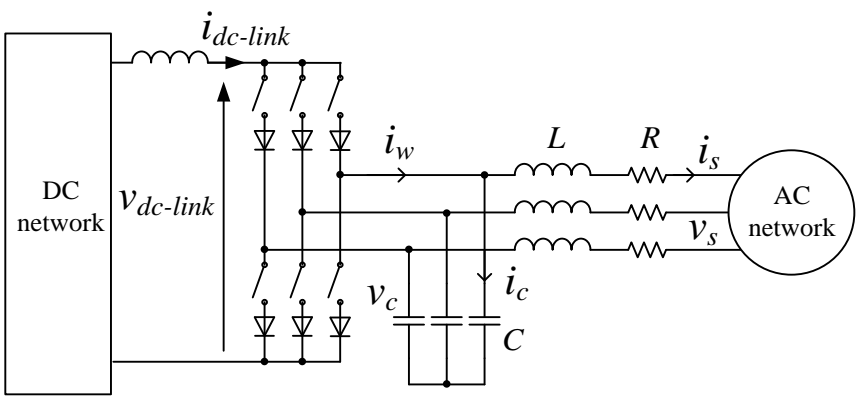

(b)

Fig. 2 (a) Full bridge DC/DC converter with a diode bridge rectifier, and (b) PWM current source inverter

\section{SYSTEM CONTROL SCHEME}

The function of the grid-side CSI is not only to deliver high quality power into the grid but also to properly control the DC link. A straightforward approach is to maintain a constant DC link current as it is an inherent CSI feature. However, as shown in Fig. 1b, the output current of the generator-side converters share the DC-link current, as the individual modules are parallel connected. If the DC link current is maintained constant by the CSIs, then the output current of each individual generator-side converter depends on the ratio of its output power to the system total power. If the power increases from one wind turbine and the other wind turbine powers remain constant, then the output current of the first wind turbine increases while the currents in the others drop. Because of the instantaneous wind power changes for each wind turbine, module interaction is inevitable. Such interaction is undesirable and degrades system performance, triggering possible system oscillations. In some extreme situations, it may cause failure of the generator-side converters. For example, consider two turbines, one delivering low power due to low wind speed, while the other output is rated power as the wind speed is high. In such a case, the wind turbine with a low power contributes a small DC link current while the other provides most of the DC link current, which could damage the generator-side converter due to increased current stressing. Due to such possible problems, the grid-side CSI should not maintain constant DC link current.

The generator-side converters are parallel connected as in a VSC based WECS. A possible way to control such a system is to maintain a constant DC link voltage. In such a case, the generator-side converters are decoupled without interaction, as their output voltage is controlled constant. Since the system is CSI based, the DC-link voltage at the CSI side is a switched voltage. The idea is to maintain the average DC-link voltage constant; therefore the generator-side converters being current sources can be readily decoupled. 


\section{A. DC Link Voltage Control}

The CSI control presented in this section is based in a synchronously rotating reference frame, where the $d$-axis is oriented to the grid voltage vector. A grid-voltage phase-locked loop (PLL) is used to obtain the instantaneous angular frequency and synchronization angle. Space vector modulation (SVM) for the CSI generates the gate signals [23].

When using SVM, the DC link voltage, $v_{d c-l i n k}$, in Fig. $2 \mathrm{~b}$ can be expressed as [24]

$$
v_{d c-l i n k}=[m]_{a b c}\left[v_{c}\right]_{a b c}^{T}
$$

where $[m]_{a b c}=\left[\begin{array}{lll}m_{a} & m_{b} & m_{c}\end{array}\right]$ is a vector matrix of the modulation indices and $\left[v_{c}\right]_{a b c}=\left[\begin{array}{lll}v_{c a} & v_{c b} & v_{c c}\end{array}\right]$ is a vector matrix of the AC-side phase voltage at the terminals of the capacitor filter.

Applying $d q$ transformations to (1) yields

$$
v_{d c-l i n k}=[m]_{d q}\left[v_{c}\right]_{d q}^{T}=\frac{3}{2}\left(m_{d} v_{c d}+m_{q} v_{c q}\right)(2)
$$

where $[m]_{d q}=\left[\begin{array}{ll}m_{d} & m_{q}\end{array}\right]$ are the $d q$ modulation indices, and $\left[v_{c}\right]_{d q}=\left[\begin{array}{ll}v_{c d} & v_{c q}\end{array}\right]$ are the $d q$ components of AC voltage $v_{c}$. Equation (2) is valid in the linear range of the modulation indices when $m_{d}^{2}+m_{q}^{2} \leq 1$. By controlling $m_{d}$, the DC link voltage can be regulated, while $m_{q}$ is used to control the reactive power. A basic technique is to send the error between the actual DC link voltage and reference voltage to a PI controller to generate the CSI gating signals. However, the DC link voltage contains CSI high-frequency switching frequency and a small magnitude $300 \mathrm{~Hz}$ low frequency harmonics (harmonic with six times the fundamental frequency) reflected from the AC grid. Using a low pass filter to obtain an average DC link voltage as a feedback signal significantly slows down controller response. Rearranging (2)

$$
m_{d}=\frac{\frac{2}{3} v_{d c-l i n k}^{*}-m_{q} v_{c q}}{v_{c d}}
$$

where $v_{d c-l i n k}^{*}$ is the reference average DC link voltage.

To achieve a fast response and disturbance rejection, (3) is used in a feed forward loop. The DC link voltage control block diagram is shown in Fig. 3. As the average DC link voltage is controlled constant, the DC and AC side powers are balanced, and the captured energy is delivered into the grid instantaneously. In other words, the active power is controlled.

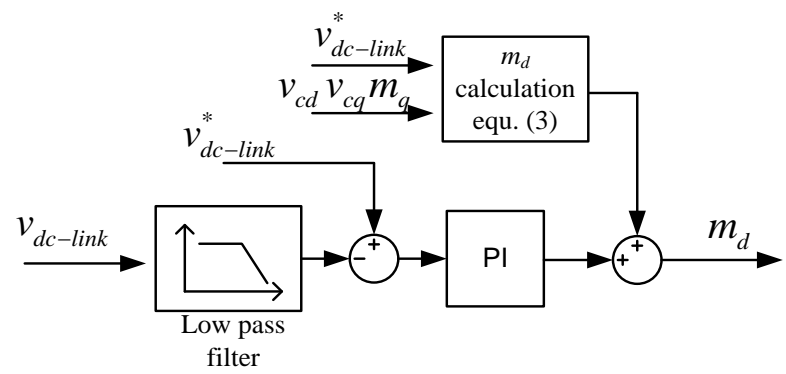

Fig. 3 DC link voltage control block diagram.

\section{B. Reactive Power Control}

The reactive power should be controlled at zero during normal operation or to a specified value when required by the grid. Using a $d q$ transformation, the reactive power can be expressed as

$$
Q=\frac{3}{2}\left(v_{s q} i_{s d}-v_{s d} i_{s q}\right)
$$

where $v_{s d}, v_{s q}$ are the grid voltage $d q$ components and $i_{s d}, i_{s q}$ are the grid current $d q$ components. With the synchronous reference frame aligned to the $d$-axis, the grid voltage $q$-axis component is zero, therefore (4) can be written as

$$
Q=-\frac{3}{2} v_{s d} i_{s q}
$$

As the AC side capacitors decouple the CSI and the grid, $i_{s q}$ cannot be controlled directly. Applying Kirchhoff's current law at the capacitor nodes in Fig. 4.

$$
\begin{aligned}
& i_{w d}=i_{c d}+i_{s d} \\
& i_{w q}=i_{c q}+i_{s q}
\end{aligned}
$$

where $i_{w d}$ and $i_{w q}$ are the CSI output current $d q$ components and $i_{c d}$ and $i_{c q}$ are the capacitor current $d q$ components.

$i_{c d}$ and $i_{c q}$ can be expressed as

$$
\begin{aligned}
& i_{c d}=C \frac{d}{d t} v_{c d}-\omega C v_{c q} \\
& i_{c q}=C \frac{d}{d t} v_{c q}+\omega C v_{c d}
\end{aligned}
$$

$v_{c d}$ and $v_{c q}$ can be expressed as

$$
\begin{aligned}
& v_{c d}=L \frac{d}{d t} i_{s d}-\omega L i_{s q}+v_{s d}+R i_{s d} \\
& v_{c q}=L \frac{d}{d t} i_{s q}+\omega L i_{s d}+v_{s q}+R i_{s q}
\end{aligned}
$$

Assuming steady state, all derivatives can be set to zero. Substituting (10) and (11) into (8) and (9), gives

$$
\begin{aligned}
& i_{c d}=-\omega C\left(\omega L i_{s d}+v_{s q}+R i_{s q}\right) \\
& i_{c q}=\omega C\left(-\omega L i_{s q}+v_{s d}+R i_{s d}\right)
\end{aligned}
$$

Substituting (12) and (13) into (6) and (7) with $v_{s q}=0$, the relationship between $i_{w d}, i_{w q}$ and $i_{s d}, i_{s q}$ can be obtained [17].

$$
\begin{gathered}
i_{w d}=\left(1-\omega^{2} C L\right) i_{s d}-\omega C R i_{s q} \\
i_{w q}=\left(1-\omega^{2} C L\right) i_{s q}+\omega C R i_{s d}+\omega C v_{s d}
\end{gathered}
$$

Rearranging (14) and (15), $i_{w q}$ can be expressed as a function of $i_{w d}$ and $i_{s q}$

$$
i_{w q}=\left(1-\omega^{2} C L+\frac{\omega^{2} C^{2} R^{2}}{1-\omega^{2} C L}\right) i_{s q}+\frac{\omega C R}{1-\omega^{2} C L} i_{w d}+\omega C v_{s d}
$$


$i_{w d}$ and $i_{w q}$ are functions of $m_{d}$ and $m_{q}$ respectively

$$
\begin{aligned}
& i_{w d}=m_{d} i_{d c-\text { link }} \\
& i_{w q}=m_{q} i_{d c-\text { link }}
\end{aligned}
$$

Substituting (17) and (18) into (16)

$$
\begin{aligned}
& m_{q}=\left(1-\omega^{2} C L+\frac{\omega^{2} C^{2} R^{2}}{1-\omega^{2} C L}\right) \frac{i_{s q}}{i_{d c-l i n k}}+ \\
& \frac{\omega C R}{1-\omega^{2} C L} m_{d}+\frac{\omega C v_{s d}}{i_{d c-\text { link }}}
\end{aligned}
$$

From (19), if the required $i_{s q}$ is known, then $m_{q}$ is obtained.

The reactive power control block diagram is shown in Fig. 4. The error between the reference reactive power and actual reactive power is fed to a PI controller. The result is used to obtain $m_{q}$ based on (19)

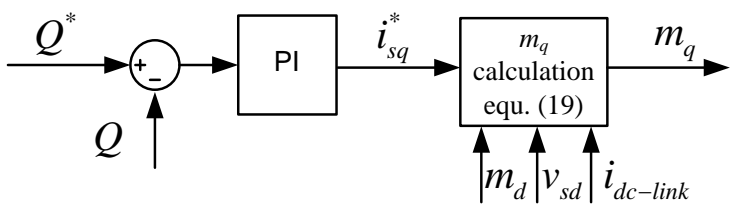

Fig. 4 Reactive power control block diagram.

\section{Complete Proposed CSI Control System}

The complete CSI control diagram is shown in Fig. 5. The obtained $d q$ axis modulation indices, $m_{d}, m_{q}$ are then fed to the SVM block to generate the CSI gating signals.

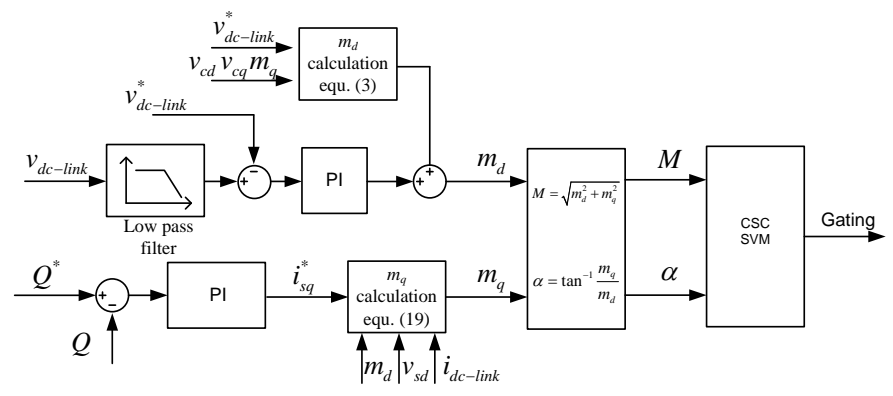

Fig. 5 CSI control diagram.

From Fig. 5, it can be concluded that the control signals $m_{d}$ and $m_{q}$ are coupled, so there is potential for interaction. Assume there is a disturbance $\Delta m_{q}$ at the output of the reactive power control loop. This disturbance will be transferred to the DC link voltage control loop and cause a disturbance $\Delta m_{d}$ in the $d$ axis modulation index, $m_{d}$. This $\Delta m_{d}$ is fed back to the reactive power control loop, causing disturbance. From (3) and (19), a $\Delta m_{q}$ disturbance results in a $\Delta m_{q}^{\prime}$ signal, which can be expressed as

$$
\Delta m_{q}^{\prime}=-\frac{\omega C R}{1-\omega^{2} C L} \frac{v_{c q}}{v_{c d}} \Delta m_{q}
$$

If $v_{c d}>v_{c q}$ and $\left(1-\omega^{2} C L\right) \gg \omega C R$, a disturbance in the reactive power loop will not cause oscillation. The same analysis can be applied to the DC link voltage control loop, and the same result is obtained. Therefore the CSI control system in Fig. 5 is stable.

\section{Generator Side Converter Control}

As the DC link is controlled by the CSI, the task of the generator side converter is to control the associated wind turbine to track its MPP and inject current into the DC link. Basically there are three types of maximum power point tracking (MPPT) algorithms [25], namely, tip speed ratio (TSR), hill-climbing searching (HCS), and power signal feedback (PSF). The three different control strategies have specific advantages and disadvantages and are suitable for different power rating WECSs. As the MPPT is not the concern of this paper, for simplicity, in the proposed system it is assumed that the DC rectifier side current is sensed and the corresponding DC rectifier side voltage reference is given by a pre-defined look-up table [26].

The converter control block diagram is shown in Fig. 6. The outer voltage control loop controls the DC/DC converter input voltage for MPPT; while the inner current control loop regulates the output inductor current, $i_{d c-o u t}$. Because the wind turbine mechanical assembly has a larger time constant than the electrical part, the outer loop has a smaller bandwidth than the inner loop. Thus the control system is stable. The main benefit of including the inner current loop is that the converter output current is defined. Therefore the DC link current is also defined, considering the CSI controls the DC link voltage only. Also, as the diode rectifier is used, it causes large low frequency DC current ripple, which leads to DC link current oscillations. With the inner current loop, this current ripple can be suppressed and does not propagate into the DC link.

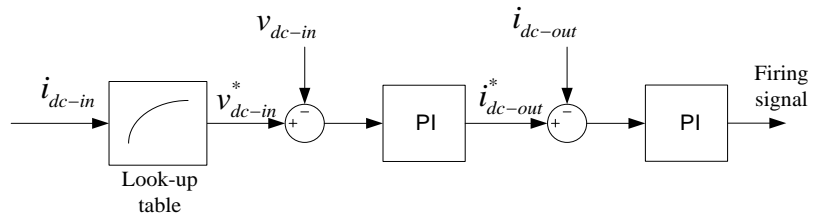

Fig. 6 Full bridge converter MPPT control block diagram.

\section{SimUlation}

The proposed WECS with its controllers is simulated in Matlab/Simulink software. The WECS includes three $16 \mathrm{~kW}$ wind turbine modules and a $50 \mathrm{~kW}$ CSI, as shown in Fig. 7. The CSI stabilizes the average DC link voltage and controls the reactive power, while the DC/DC converter controls its associated wind turbine. The system parameters are summarized in Table I.

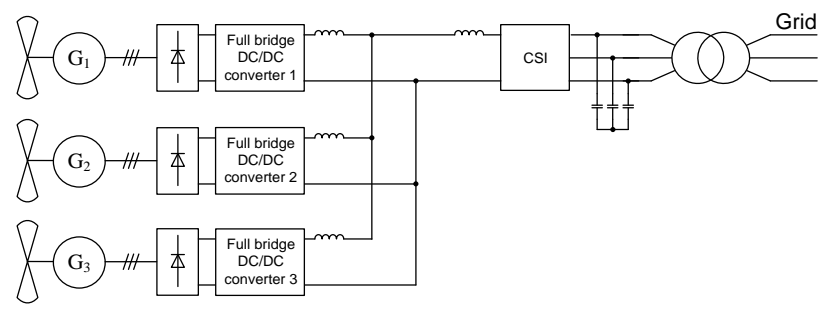

Fig. 7 Proposed system in simulation 
Table I System parameters in simulation

\begin{tabular}{|c|c|c|}
\hline Parameters & \multicolumn{2}{|c|}{ Values } \\
\hline \multicolumn{3}{|l|}{ PMSG } \\
\hline Power rating & 16 & $\mathrm{~kW}$ \\
\hline Stator inductance & 13.47 & $\mathrm{mH}$ \\
\hline Voltage rating & 490 & $\mathrm{~V}$ \\
\hline Stator resistance & 0.672 & $\Omega$ \\
\hline PMSG flux & 2.39 & $\mathrm{~Wb}$ \\
\hline Pole pairs & 12 & \\
\hline Turbine inertia & 50 & $\mathrm{kgm}^{2}$ \\
\hline \multicolumn{3}{|c|}{ Full bridge converter } \\
\hline Input capacitor & 1000 & $\mu \mathrm{F}$ \\
\hline Output inductor & 10 & $\mathrm{mH}$ \\
\hline $\begin{array}{l}\text { Transformer transformation } \\
\text { ratio }\end{array}$ & $1: 2.2$ & \\
\hline Switching frequency & 10 & $\mathrm{kHz}$ \\
\hline \multicolumn{3}{|l|}{ CSI } \\
\hline Power rating & 50 & $\mathrm{~kW}$ \\
\hline Phase RMS voltage & 796 & $\mathrm{~V}$ \\
\hline Phase RMS current & 36.3 & $\mathrm{~A}$ \\
\hline Frequency & 50 & $\mathrm{~Hz}$ \\
\hline Grid-side capacitor & 125 & $\mu \mathrm{F}$ \\
\hline Grid-side line inductance & 4 & $\mathrm{mH}$ \\
\hline DC link inductor & 10 & $\mathrm{mH}$ \\
\hline DC link resistance & 0 & $\Omega$ \\
\hline CSI switch frequency & 4 & $\mathrm{kHz}$ \\
\hline Average DC link voltage & 750 & $\mathrm{~V}$ \\
\hline
\end{tabular}

The simulation results for the three wind turbines are shown in Figs. 8 to 10. Fig. 8 parts a to $\mathrm{c}$ show the wind speed, rotor speed, and $C_{p}$ of turbine 1 . The wind speed remains at $14 \mathrm{~m} / \mathrm{s}$ and the $C_{p}$ is at maximum value [27]. Figs. 9 and 10 show the corresponding simulation results for turbines 2 and 3 , respectively, where turbine 2 has a wind speed change at $1 \mathrm{~s}$, while turbine 3 has a wind speed change at $2 \mathrm{~s}$. The rotor speed is regulated by the full bridge DC/DC converter to track the MPP as shown in Figs. 9b and 10b. The simulation results confirm the three wind turbines are decoupled where power change in one wind turbine does not affect another turbine.

Also, the simulation results of the corresponding three generator side converters are also shown in Figs. 8 to 10, showing DC/DC converter input voltage, input current, and output current. The three wind turbines are decoupled, and each DC/DC converter tracks the MPP by regulating the converter input voltage and current. The input current has large low frequency ripple, while any low frequency ripple is suppressed on the output side.
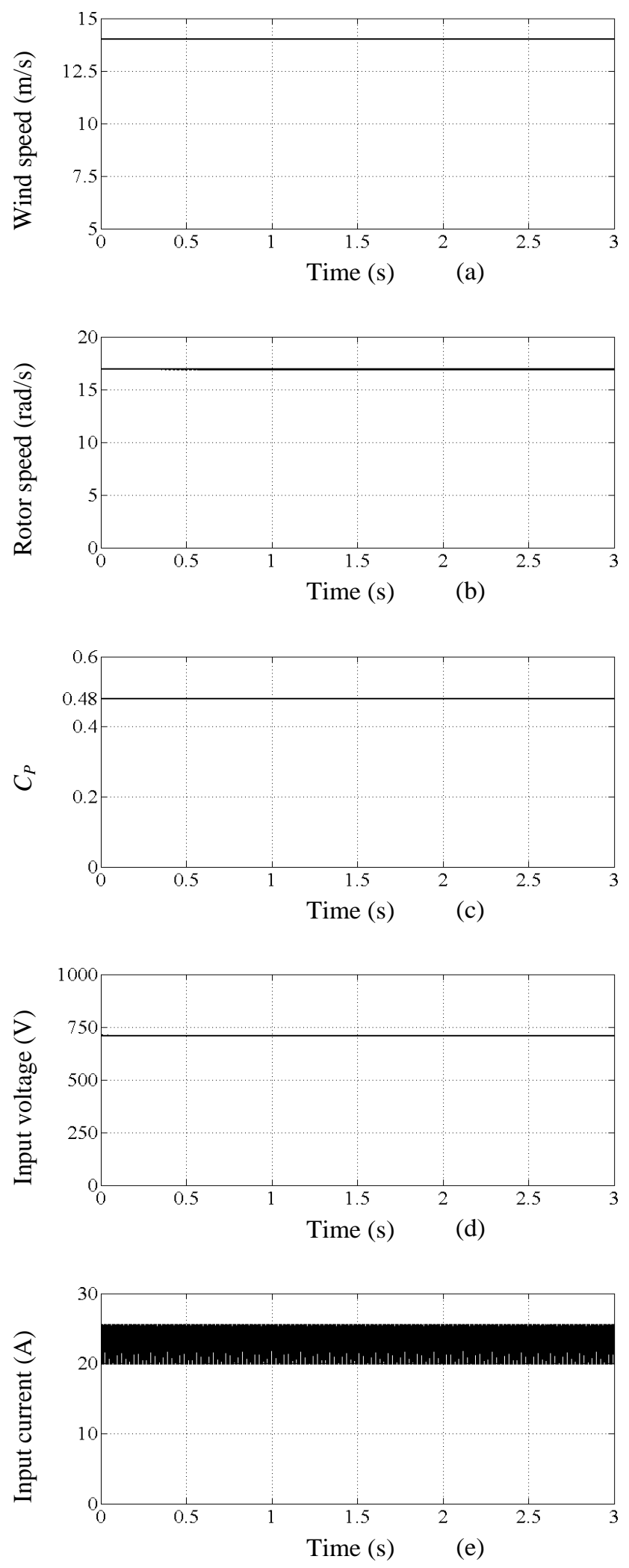


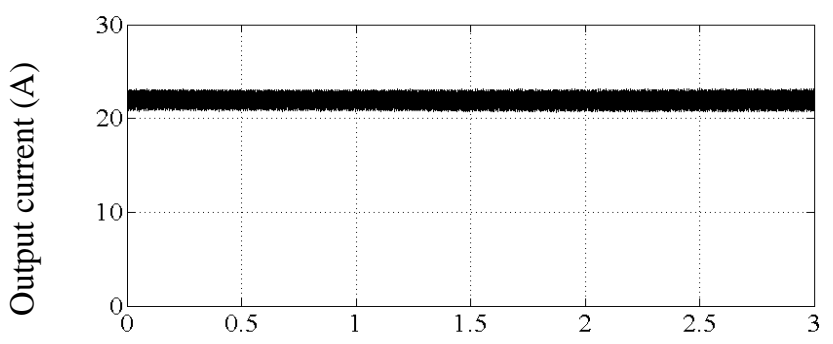

Time (s)

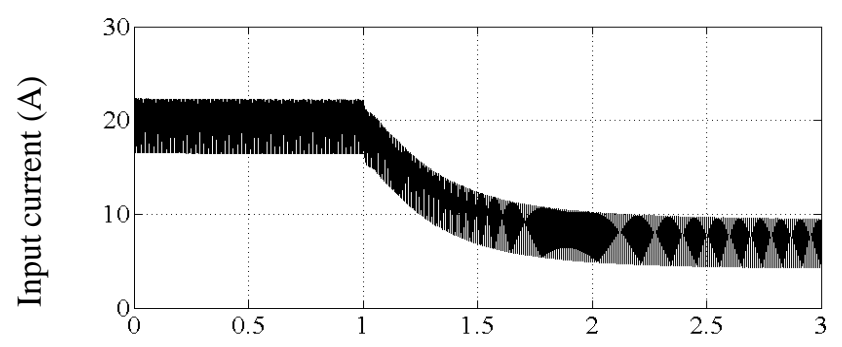

Time (s)

(e)

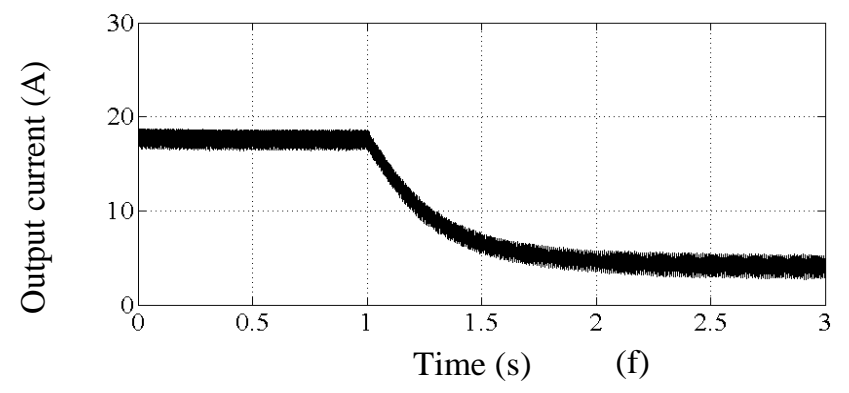

Fig. 9 Turbine 2 simulation results: (a) wind speed, (b) rotor speed, (c) $C_{p}$, (d) full bridge converter input voltage, (e) full bridge converter input current, and (f) full bridge converter output current.
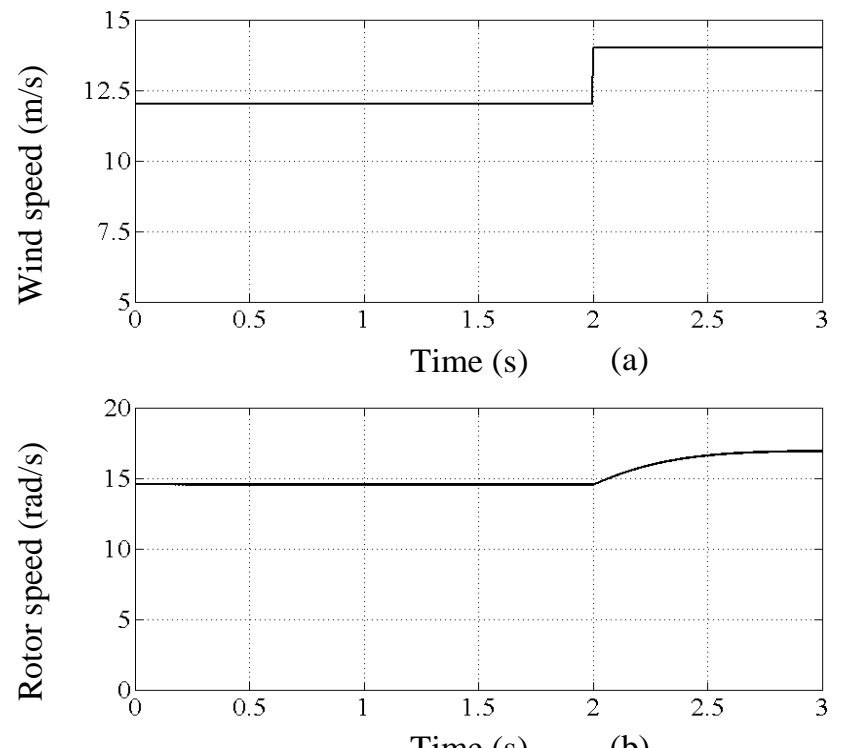

Time (s)

(b)

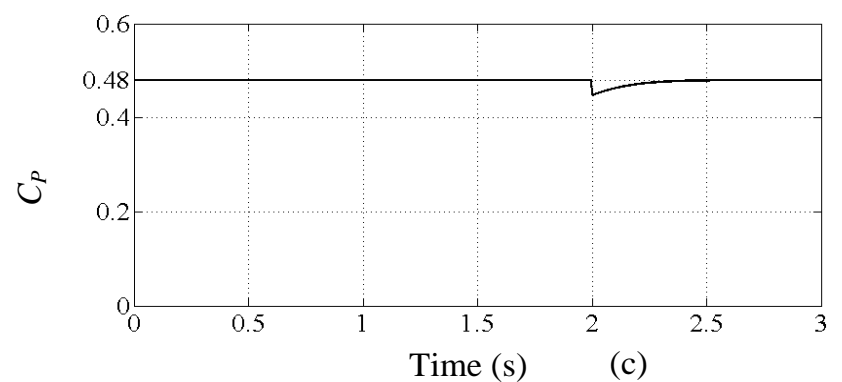




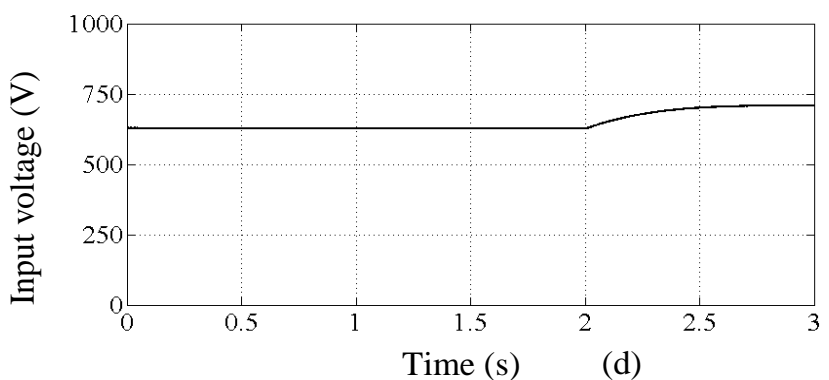

Time (s)

(d)
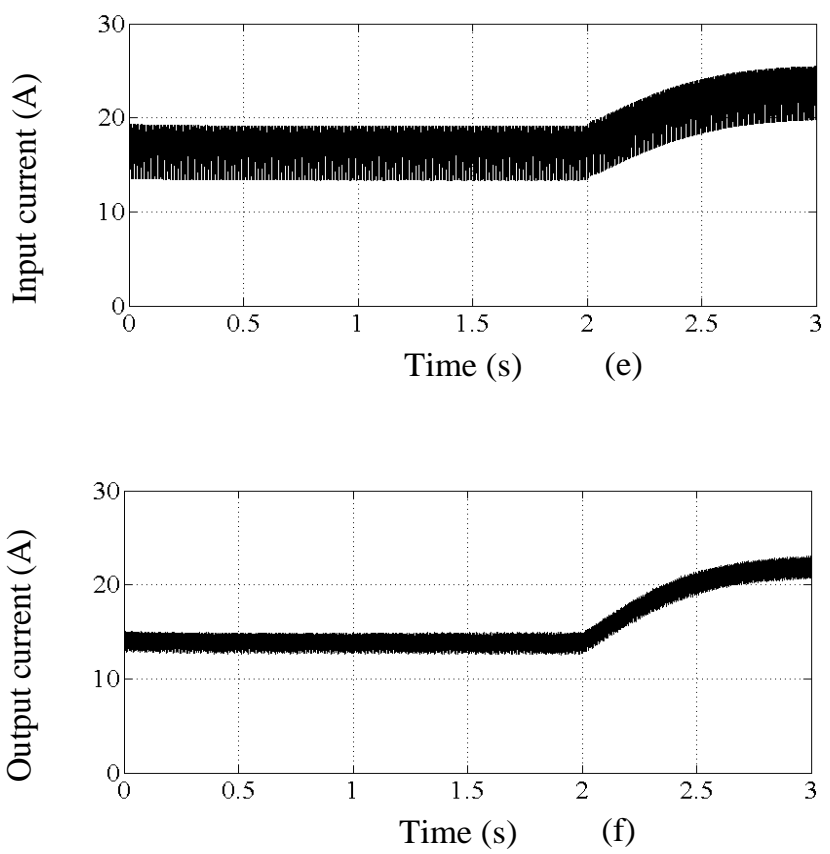

Fig. 10 Turbine 3 simulation results: (a) wind speed, (b) rotor speed, (c) $C_{p}$, (d) full bridge converter input voltage, (e) full bridge converter input current, and (f) full bridge converter output current.

The average DC link voltage is maintained at $750 \mathrm{~V}$ by the CSI. Since the CSI switching frequency is $4 \mathrm{kHz}$, a $400 \mathrm{~Hz}$ cut-off frequency low pass filter is used to obtain the average DC link voltages. The average generator side and inverter side DC link voltages are shown in Fig. 11 parts a and b. As the DC link resistance is neglected, there is no voltage drop between the generator and the inverter sides. Fig. 11c shows the DC link current, which varies with wind speed changes. Fig. 11d shows the CSI active and reactive powers. The active power flow between the DC and AC sides is balanced, while the reactive power is controlled at zero. The active and reactive powers are decoupled and independently controlled. The AC side capacitor voltage and output phase current are shown in Fig. 11 parts e and $\mathrm{f}$, with a THD of $1.18 \%$ and $0.22 \%$, respectively. $d q$ values are shown in Fig. 11 parts $g$ and $h$.
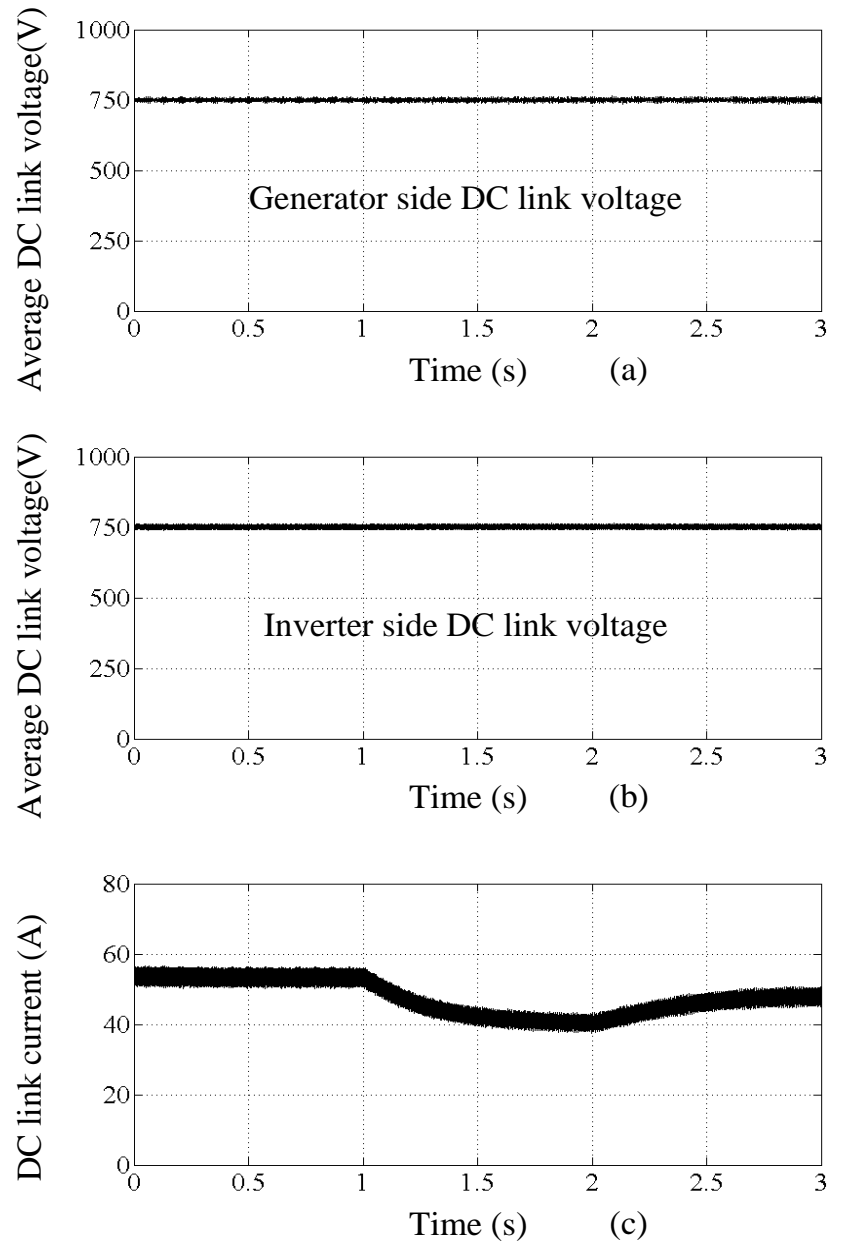

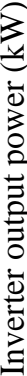
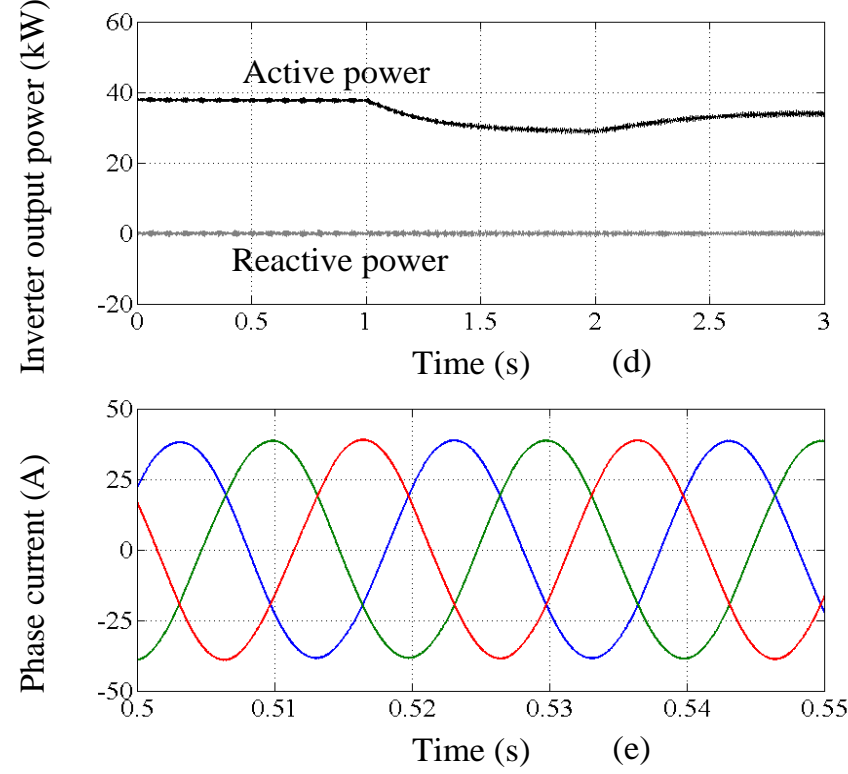

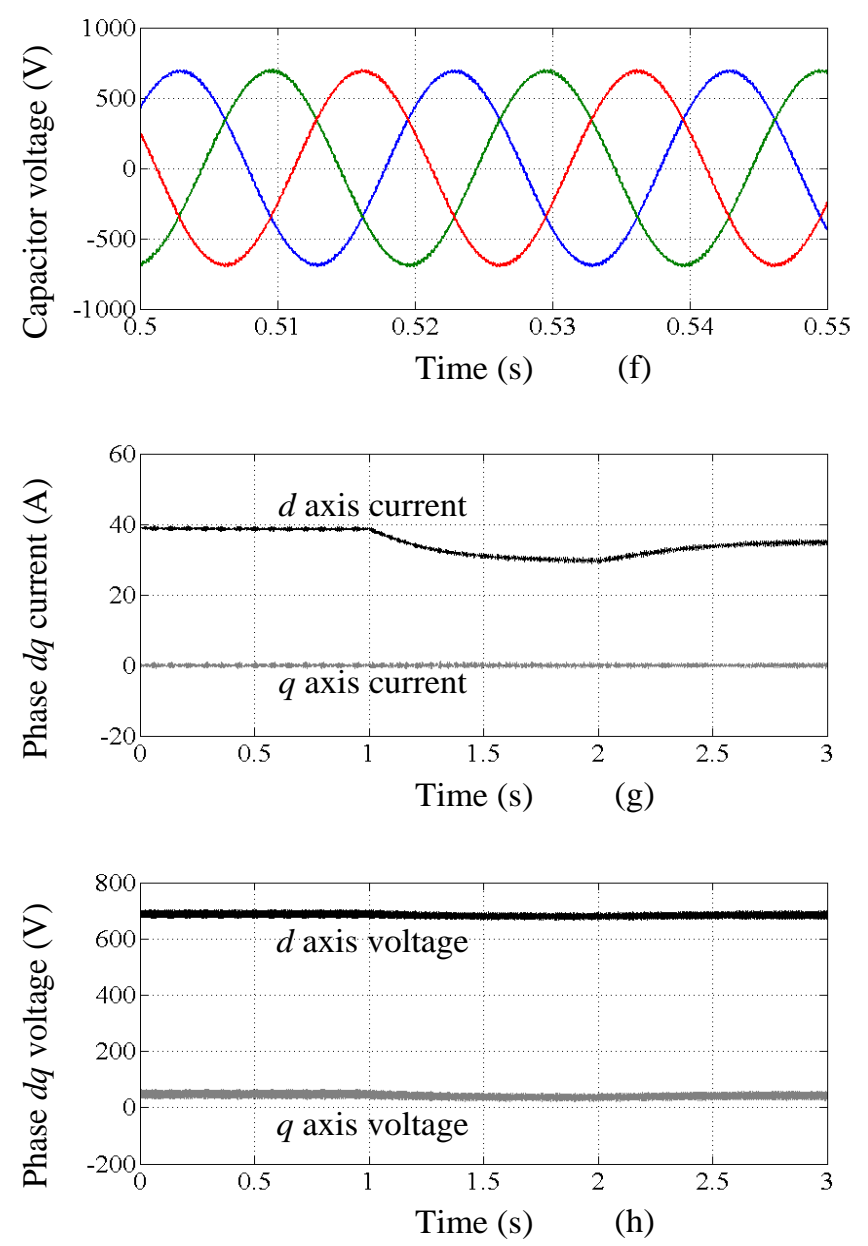

Fig. 11 CSI simulation results: (a) generator side average DC link voltage, (b) inverter side average DC link voltage, (c) DC link current,

(d) inverter output power, (e) three phase currents, (f) three phase capacitor voltages, (g) phase $d q$ current, and (h) capacitor $d q$ voltage.

The simulation results confirm the ability of the proposed system to achieve good dynamic performance. The CSI is able to control the average DC link voltage to a constant value, while all three parallel connected wind turbines are individually controlled for MPPT without any interaction.

\section{EXPERIMENTATION}

The current source inverter test rig shown in Fig. 12 is used to verify the proposed control techniques for the grid connected CSI. The input is a DC voltage source series connected with a resistor, allowing an adjustable input power. The output is connected to an AC transformer and variac for grid interfacing. The test rig system parameters are summarized in Table II.

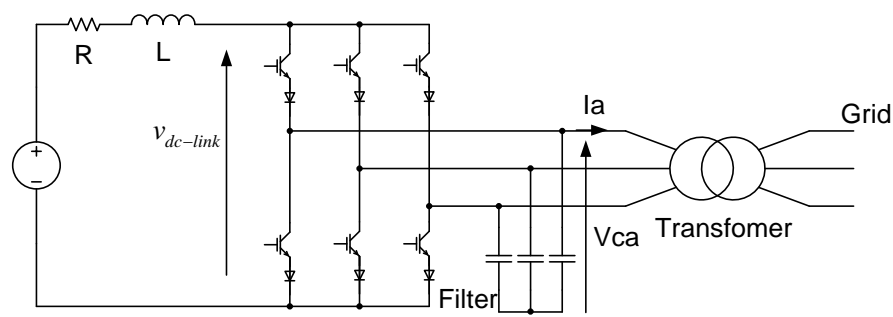

Fig. 12 CSI test rig schematic.

Table II CSI test rig parameters.

\begin{tabular}{|c|c|c|}
\hline Parameters & \multicolumn{2}{|c|}{ Values } \\
\hline Power rating & 1.8 & $\mathrm{~kW}$ \\
\hline DC link inductor & 10 & $\mathrm{mH}$ \\
\hline Filter capacitor & 40 & $\mu \mathrm{F}$ \\
\hline Grid voltage (rms) & 110 & $\mathrm{~V}$ \\
\hline Grid voltage frequency & 50 & $\mathrm{~Hz}$ \\
\hline Switching frequency & 4 & $\mathrm{kHz}$ \\
\hline DC link resistance & 8 & $\Omega$ \\
\hline Average DC link voltage, $v_{d c-l i n k}$ & 200 & $\mathrm{~V}$ \\
\hline
\end{tabular}

\section{A. Full Active Power}

The practical results in Figs. 13 and 14 show the system in steady state delivering full rated active power. Fig. 13a shows the AC voltage and current. There is no phase shift between the phase current and voltage, demonstrating that the reactive power is controlled to be zero. Fig. 13 parts $\mathrm{b}$ and $\mathrm{c}$ show the DC link voltage and DC link current. The system parameters sensed via the DSP are given in Fig. 14, with the values stable as the system is in steady state. The CSI efficiency is about $95 \%$.
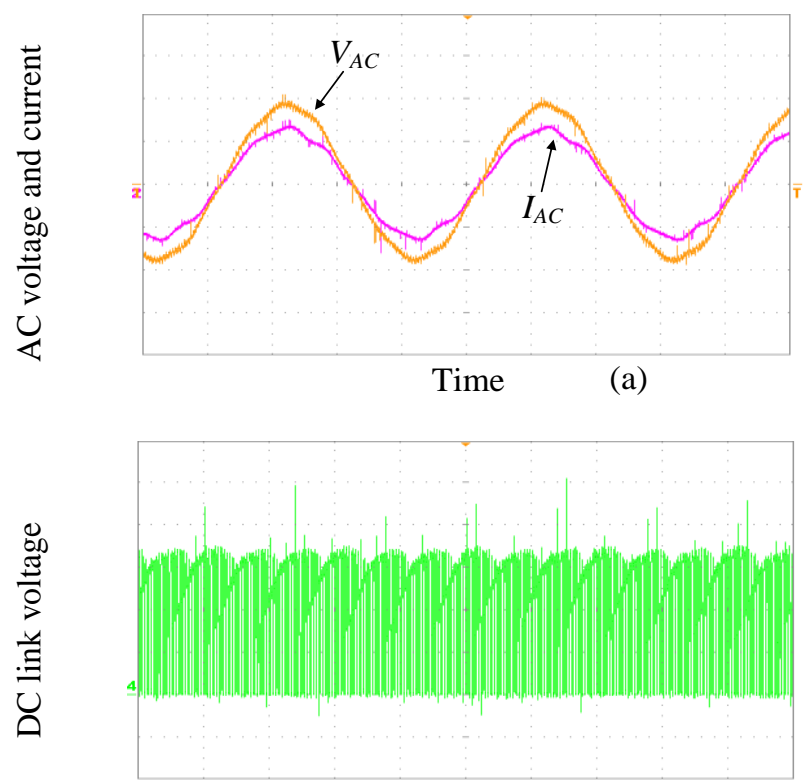

Time (b) 


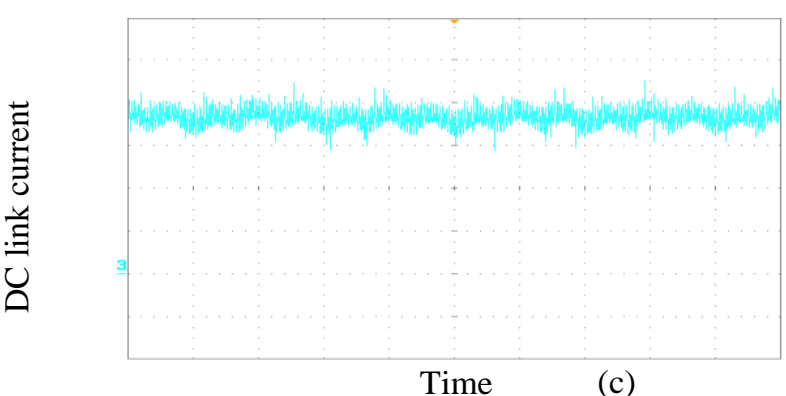

Fig. 13 Practical results in steady state $(5 \mathrm{~ms} / \mathrm{div})$ : (a) AC voltage and current $(100 \mathrm{~V} / \mathrm{div}, 5 \mathrm{~A} / \mathrm{div})$,

(b) DC link voltage (100V/div), and (c) DC link current (2.5A/div).
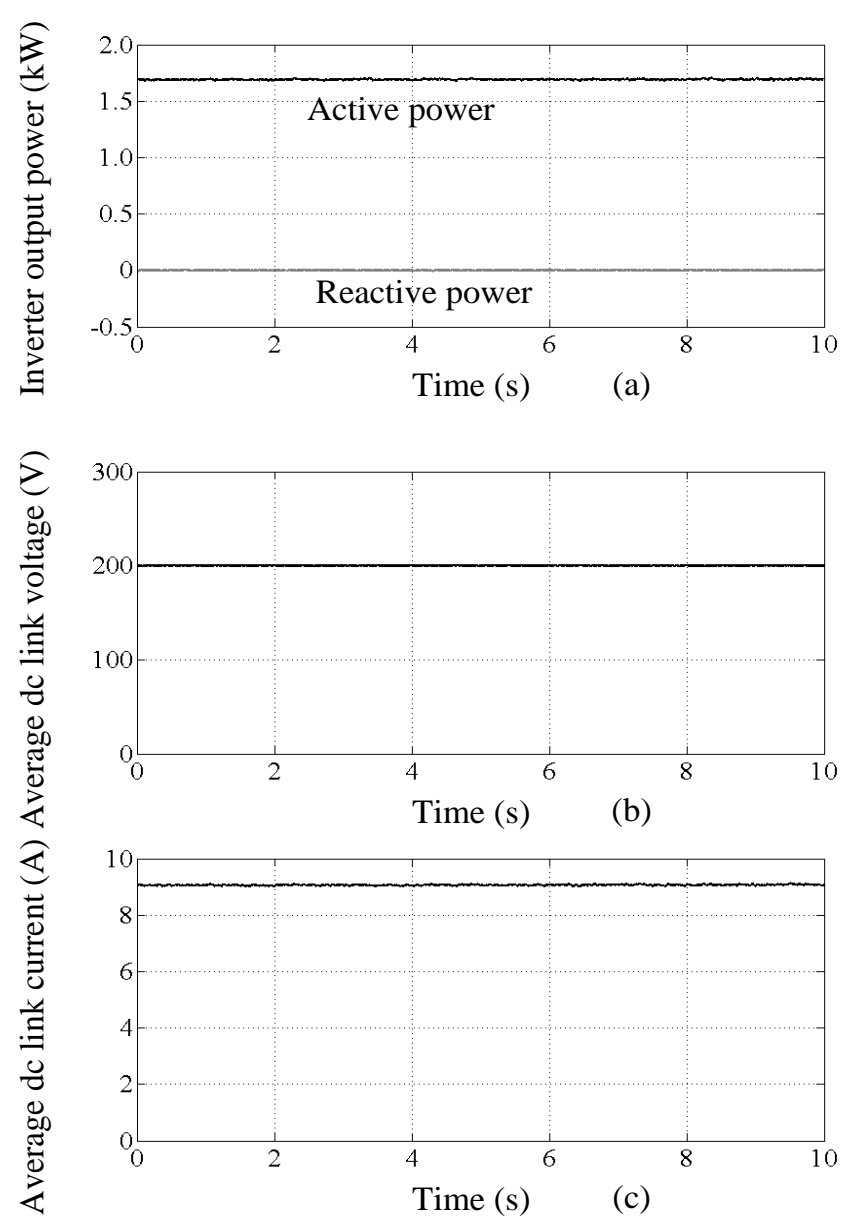

Fig. 14 Practical results sensed by DSP: (a) inverter output power,

(b) average DC link voltage, and (c) average DC link current.

The practical results from a power analyzer are summarized in Table III. The phase voltage and current THD's are mainly caused by the grid voltage distortion rather than the CSI, as the laboratory grid voltage is distorted (2.5\% THD). When the CSI is not operating (hence the output capacitive filter dominates), the grid voltage and phase current are as shown in Fig. 15a. The grid voltage $2.5 \%$ THD results in a $11.7 \%$ THD distorted current. The corresponding simulation phase current, using the same system parameters, is shown in Fig. 15b. The practical and simulation results correspond, verifying that the current distortion, when the CSI is not operating, is mainly caused by the grid voltage rather than other factors. This distorted current has a significant effect on the phase current when the system is operating. In the practical implementation, when the CSI injects full rated active power to the grid, its output current is sinusoidal with higher amplitude and smaller THD. Therefore the superposition of the CSI output current and original filter current results in the current shown in Fig. 13a, the 4.0\% THD of which is mainly caused by the grid voltage distortion rather than the proposed controller. The $0.08 \mathrm{kVAr}$ reactive power shown in Table III is also mainly associated with the harmonic voltage and current rather than their phase shift.

Table III Practical results.

\begin{tabular}{|c|c|c|}
\hline Items & \multicolumn{2}{|c|}{ Specification } \\
\hline Active power & 1.74 & $\mathrm{~kW}$ \\
\hline Reactive power & 0.08 & $\mathrm{kVAr}$ \\
\hline Phase voltage THD & $3.2 \%$ & \\
\hline Phase current THD & $4.0 \%$ & \\
\hline Filter capacitor voltage (rms) & 129.3 & $\mathrm{~V}$ \\
\hline Power factor & 0.998 & \\
\hline
\end{tabular}
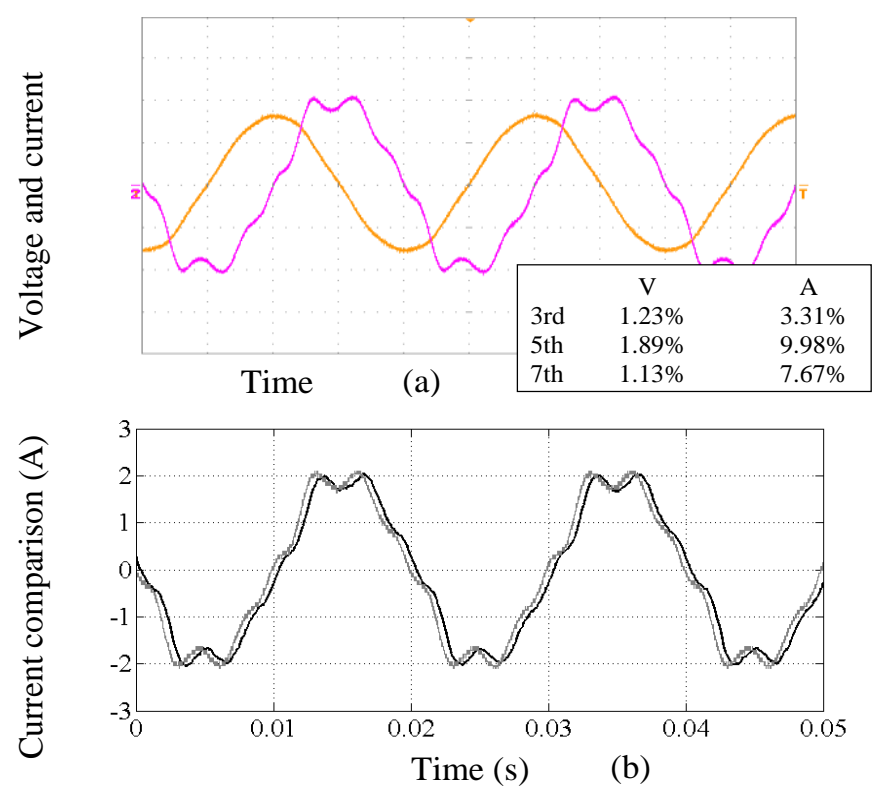

Fig. 15 Voltage and current distortion:

(a) grid voltage and phase current (100V/div, 1A/div, $5 \mathrm{~ms} / \mathrm{div})$ and (b) comparison of actual phase current and simulation result.

\section{B. Input Active Power Change}

If there is an input active power change, the proposed CSI controller should maintain the average DC link voltage constant. The practical results in Fig. 16 show the active power increasing from $1.1 \mathrm{~kW}$ to $1.7 \mathrm{~kW}$ (about $55 \%$ ) within 2 seconds, which is a reasonable interval considering the long time constant of a wind turbine. Fig. 16a shows system active power change while the reactive power is controlled at 0 . Fig. $16 \mathrm{~b}$ shows that the average DC link voltage is controlled at $200 \mathrm{~V}$ without any change, while Fig. 16c shows the rising average DC link current. 


\section{0}

$$
1.5
$$

1.0
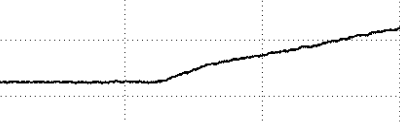

Active power

$$
0.5
$$
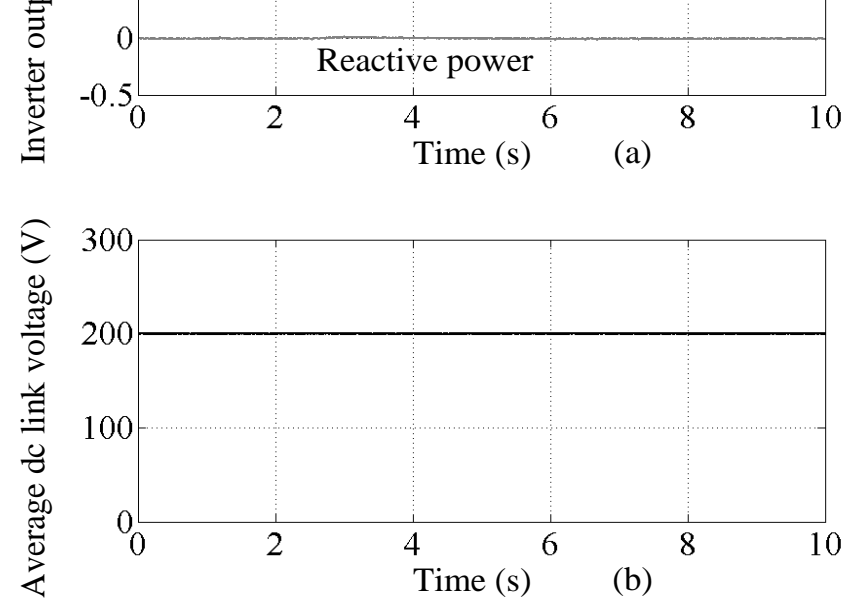

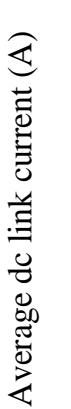

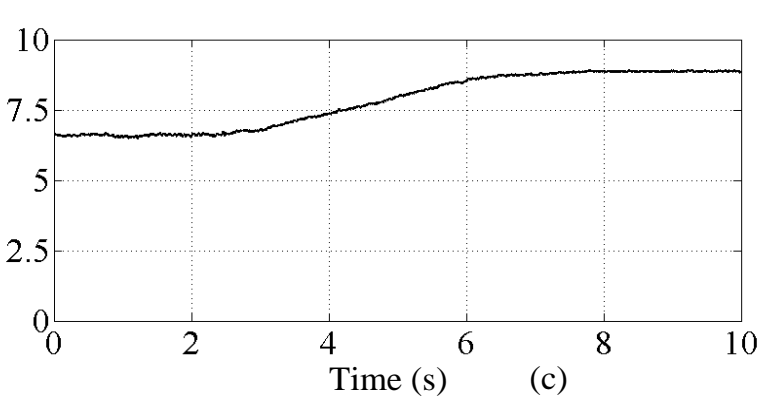

Fig. 16 Practical results with active power change:(a) inverter output power, (b) average DC link voltage, and (c) average DC link current.

\section{Reactive Power Control}

As required by the grid code, a wind farm must be able to control its reactive power. The following practical results demonstrate the ability of the proposed system to fully control reactive power. The average DC link voltage is controlled to $30 \mathrm{~V}$, needed to limit the active power to a near zero value. A reactive power reference (dotted line on Fig. 17a) to the controller can demand generated or consumed reactive power. Fig. 17a shows the transient response of system output power. The active power is maintained at $0.24 \mathrm{~kW}$, while the reactive power is controlled according to the reference ( $0 \mathrm{kVAr}$ between $0 \mathrm{~s}$ to $1 \mathrm{~s}, 1.6 \mathrm{kVAr}$ between $1 \mathrm{~s}$ to $5 \mathrm{~s}$, and $-1.2 \mathrm{kVAr}$ between $5 \mathrm{~s}$ to 10s). The average DC link voltage and current are shown in Fig. 17 parts b and c, respectively. The small voltage disturbance is due to the reactive power step change.
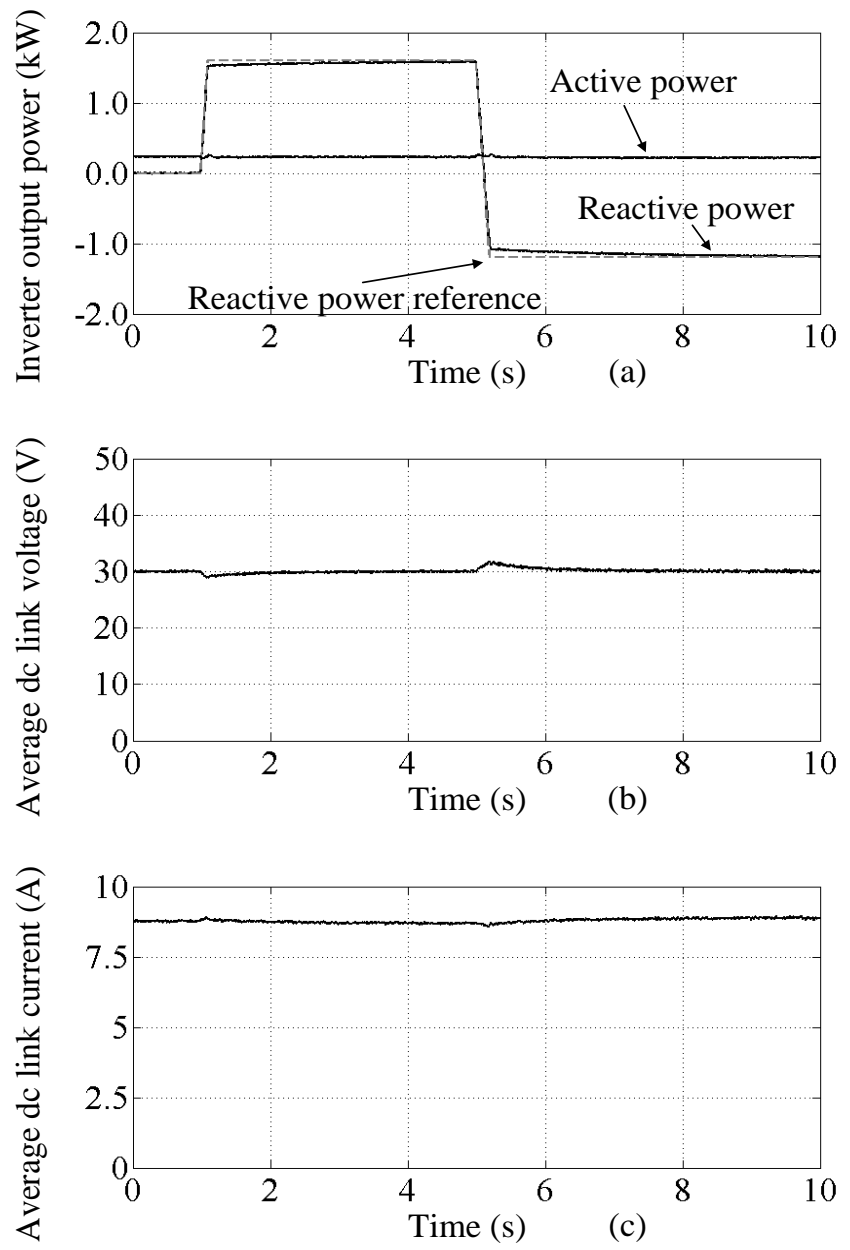

Fig. 17 Practical results of reactive power control (via dsp): (a) output power, (b) average DC link voltage, and (c) average DC link current.

When the system supplies reactive power into the grid during the period 1s to $5 \mathrm{~s}$ as in Fig. 17a, the AC voltage and current are as shown in Fig. 18a with current lagging the voltage. Fig. 18 parts $\mathrm{b}$ and $\mathrm{c}$ show the DC link voltage and current, respectively. The system power analyzer experimental data is summarized in Table V.

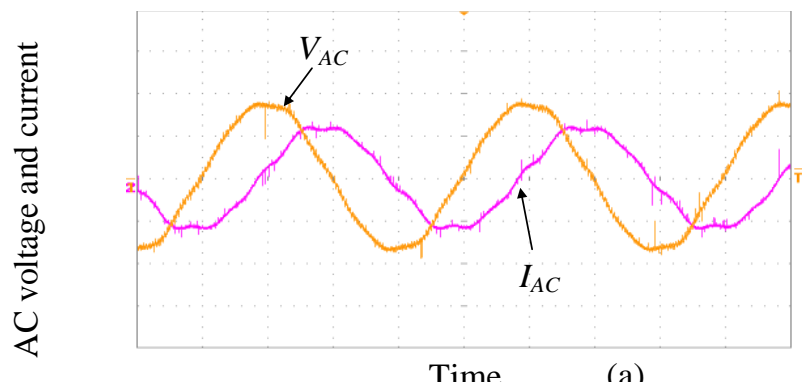

Time (a) 


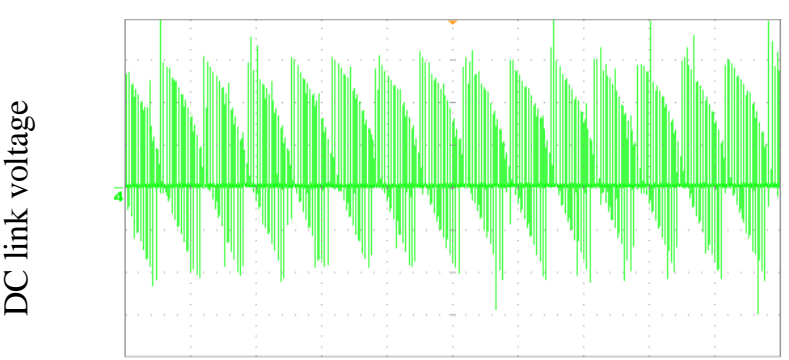

Time

(b)

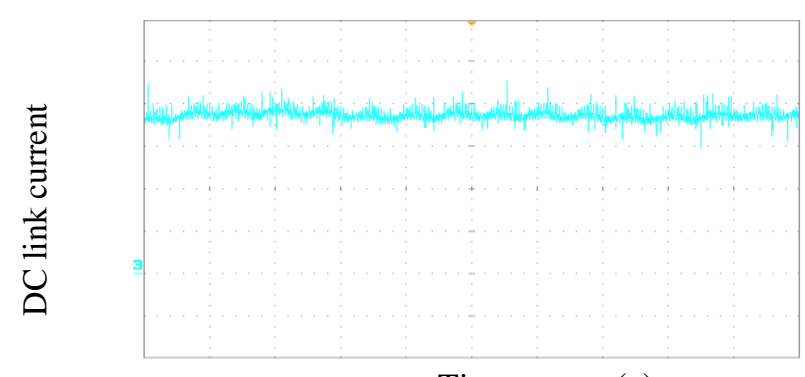

Time

(c)

Fig. 18 Practical supply of reactive power (5ms/div): (a) AC voltage and current, $(100 \mathrm{~V} / \mathrm{div}, 5 \mathrm{~A} / \mathrm{div})$

(b) DC link voltage (100V/div) and (c) DC link current (2.5 A/div).

Table IV Practical results when supplying reactive power.

\begin{tabular}{|c|c|c|}
\hline Items & \multicolumn{2}{|c|}{ Specification } \\
\hline Active power & 0.235 & $\mathrm{~kW}$ \\
\hline Reactive power & +1.589 & $\mathrm{kVAr}$ \\
\hline Phase voltage THD & $3.5 \%$ & \\
\hline Phase current THD & $4.5 \%$ & \\
\hline Capacitor voltage (rms) & 123.9 & $\mathrm{~V}$ \\
\hline Power factor & +0.146 & \\
\hline
\end{tabular}

When the system consumes reactive power from the grid during the period 5s to 10s as in Fig. 17a, the AC current leads the AC voltage as shown in Fig. 19. Fig. 19 parts b and c show the DC link voltage and current, respectively. The system data from the power analyzer is summarized in Table VI.

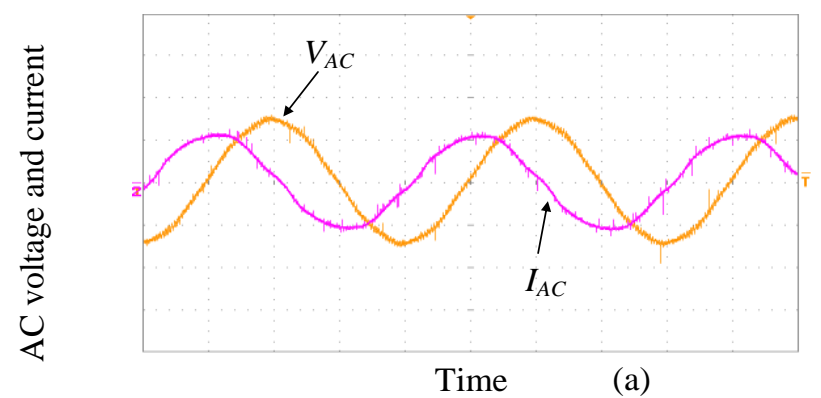

Time

(a)

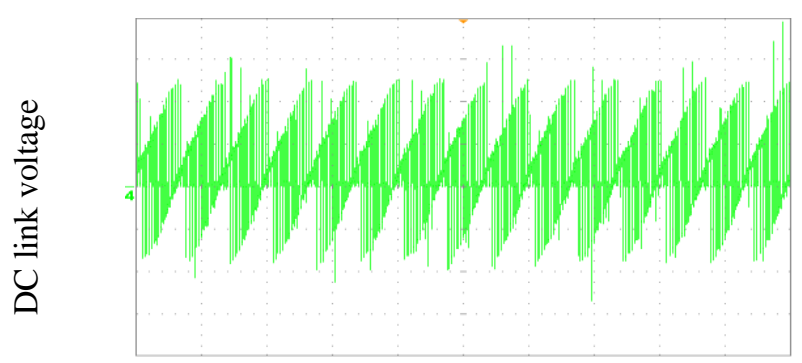

Time

(b)

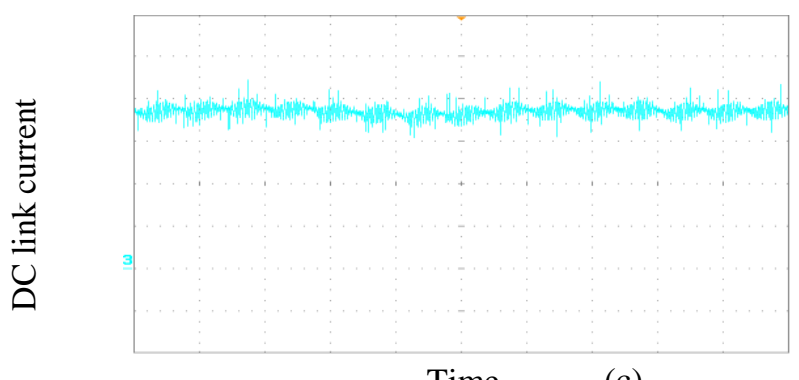

Time

(c)

Fig. 19 Practical results when consuming reactive power ( $5 \mathrm{~ms} / \mathrm{div})$ : (a) AC voltage and current (100V/div, $5 \mathrm{~A} / \mathrm{div})$, (b) DC link voltage (100V/div), and (c) DC link current (2.5A/div).

Table V Practical results when consuming reactive power.

\begin{tabular}{|c|c|c|}
\hline Items & \multicolumn{2}{|c|}{ Specification } \\
\hline Active power & 0.237 & $\mathrm{~kW}$ \\
\hline Reactive power & -1.210 & $\mathrm{kVAr}$ \\
\hline Phase voltage THD & $3.4 \%$ & \\
\hline Phase current THD & $4.2 \%$ & \\
\hline Capacitor voltage (rms) & 104.3 & $\mathrm{~V}$ \\
\hline Power factor & -0.193 & \\
\hline
\end{tabular}

Based on these practical results, the reactive power control capabilities of the proposed CSI control concept is verified.

\section{COMPARISON WITH CONVENTIONAL HVDC TRANSMISSION}

The conventional two-terminal LCC-based HVDC transmission system is shown in Fig. 20, where $I_{d}$ is the DC link current, $V_{d r}$ is the rectifier side DC link voltage, and $V_{d i}$ is the inverter side DC link voltage. Assuming an ideal system, under steady state, the rectifier $V-I$ characteristic is shown in Fig. 21a. During normal operation, the DC link current is phase angle controlled by the rectifier at $I_{d}{ }^{*}$. Simultaneously the inverter controls the DC link voltage at $V_{d r}{ }^{*}$ with a $V$-I characteristic as shown in Fig. 21a. The system operating point is where the rectifier characteristic intersects the inverter characteristic, which is at point A on Fig. 21a. Thus the DC link voltage and current can be independently controlled at the required voltage and current [28]. 


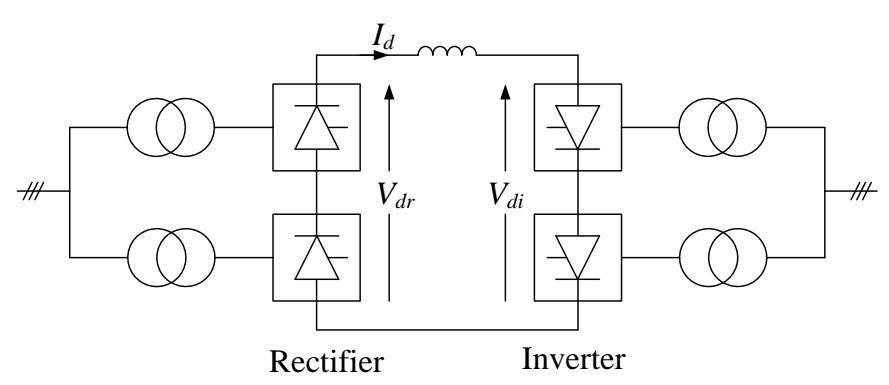

Fig. 20 Conventional two-terminal CSI-based HVDC transmission system.

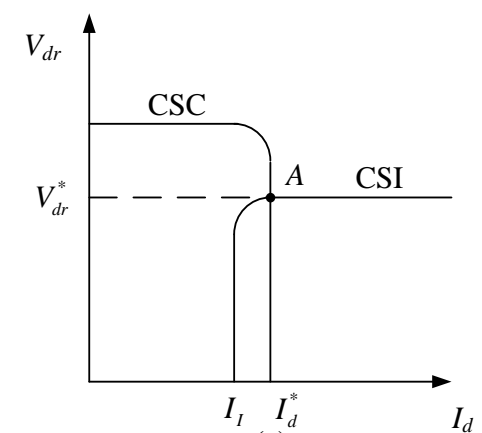

(a)

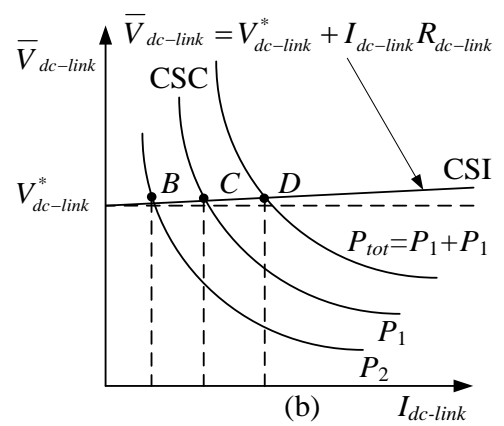

Fig. 21 Steady-state $V$ - $I$ characteristics for a two terminal HVDC system: (a) conventional rectifier/inverter characteristics and

(b) proposed system generator side converter/CSI characteristics.

In the proposed system, the CSI stiffly controls the DC link average voltage to a reference for any input DC link current, with the $V$-I characteristic shown in Fig. 21b. When considering the effect of DC link resistance, the $V-I$ characteristic of the DC link at the generator side exhibits an average voltage increase with an increasing DC link current, as shown in Fig. 21b.

Unlike conventional HVDC, the rectifier current controller does not override or dominate the grid side inverter mode of operation. For the generator side converters, which assure MPPT control, the output power is safely assumed slowly varying. The $V$-I characteristics of two converters $\left(P_{1}\right.$ and $\left.P_{2}\right)$ are shown in Fig. 21b, with different output powers $P_{1}, P_{2}$ and the total power $P_{t o t}$. Similarly the operating point of the DC link is where the characteristics intersect, point $\mathrm{D}$ showing the generator side DC link operating voltage and current. Assuming the two DC/DC converters have a common connection point, the operating voltage is same for both converters, and the operating current is the sum of the two converter output currents. Hence point B and C in Fig. 21b are the operating points for the two converters.
Therefore compared with conventional LCC-based system, in the proposed systems, the CSI stiffly controls the DC link average voltage; while the generator side converters inject all the current from the generators into the DC network, thereby allowing multi-terminal uni-directional operation.

\section{CONCLUSION}

A PWM current source based wind energy conversion system for a parallel configured HVDC application has been proposed. Similar to a voltage source based system, the generator side converters are parallel connected to a common DC transmission network. This has some of the advantages of the VSC based system, but is inherently robust to both DC and AC short circuit faults. Furthermore, this configuration overcomes some disadvantages of a current source based series connected system. A new inverter control technique was proposed based on this configuration, with independent control of average DC link voltage and reactive power. The concept and performance of the proposed system have been confirmed by system simulation. The inverter control system was further verified by practical implementation. Finally, a comparison of characteristics between the proposed system and conventional current source based HVDC systems was presented.

\section{REFERENCES}

E. Martinot, Renewables 2010 Global Status Report: DIANE Publishing Company, 2010.

G. W. E. Council, Global Wind Energy Outlook 2010: Global Wind Energy Council, 2010.

Z. Chen and E. Spooner, "Current source thyristor inverter and its active compensation system," Generation, Transmission and Distribution, IEE Proceedings-, Vol. 150, pp. 447-454, 2003.

Z. Chen, "Compensation schemes for a SCR converter in variable speed wind power systems," Power Delivery, IEEE Transactions on, vol. 19, pp. 813-821, 2004.

P. Tenca and T. A. Lipo, "Reduced cost current-source topology improving the harmonic spectrum through on-line functional minimization," in Power Electronics Specialists Conference, 2004. PESC 04. 2004 IEEE 35th Annual, 2004, pp. 2829-2835 Vol.4.

[6] P. Tenca, A. A. Rockhill, and T. A. Lipo, "Wind Turbine Current-Source Converter Providing Reactive Power Control and Reduced Harmonics," Industry Applications, IEEE Transactions on, Vol. 43, pp. 1050-1060, 2007.

[7] P. Tenca, A. A. Rockhill, T. A. Lipo, and P. Tricoli, "Current Source Topology for Wind Turbines With Decreased Mains Current Harmonics, Further Reducible via Functional Minimization," Power Electronics, IEEE Transactions on, Vol. 23, pp. 1143-1155, 2008.

[8] S. Nishikata and F. Tatsuta, "A New Interconnecting Method for Wind Turbine/Generators in a Wind Farm and Basic Performances of the Integrated System," Industrial Electronics, IEEE Transactions on, Vol. 57, pp. 468-475, 2010.

[9] J. M. Carrasco, L. G. Franquelo, J. T. Bialasiewicz, E. Galvan, R. C. P. Guisado, M. A. M. Prats, J. I. Leon, and N. Moreno-Alfonso, "Power-Electronic Systems for the Grid Integration of Renewable Energy Sources: A Survey," Industrial Electronics, IEEE Transactions on, Vol. 53, pp. 1002-1016, 2006.

[10] J. Rodriguez, S. Bernet, P. K. Steimer, and I. E. Lizama, "A Survey on Neutral-Point-Clamped Inverters," Industrial Electronics, IEEE Transactions on, Vol. 57, pp. 2219-2230, 2010.

[11] S. Kouro, M. Malinowski, K. Gopakumar, J. Pou, L. G. Franquelo, W. Bin, J. Rodriguez, Pe, x, M. A. rez, and J. I. Leon, "Recent Advances and Industrial Applications of Multilevel Converters," Industrial Electronics, IEEE Transactions on, Vol. 57, pp. 2553-2580, 2010.

[12] H. Abu-Rub, J. Holtz, J. Rodriguez, and B. Ge, "Medium-Voltage Multilevel Converters-State of the Art, Challenges, and 
Requirements in Industrial Applications," Industrial Electronics, IEEE Transactions on, Vol. 57, pp. 2581-2596, 2010.

[13] X. del Toro Garcia, A. Arias, M. G. Jayne, and P. A. Witting, "Direct Torque Control of Induction Motors Utilizing Three-Level Voltage Source Inverters," Industrial Electronics, IEEE Transactions on, Vol. 55, pp. 956-958, 2008.

[14] L. Malesani, L. Rossetto, P. Tenti, and P. Tomasin, "AC/DC/AC PWM converter with reduced energy storage in the DC link," Industry Applications, IEEE Transactions on, Vol. 31, pp. 287-292, 1995.

[15] H. Namho, J. Jinhwan, and N. Kwanghee, "A fast dynamic DC-link power-balancing scheme for a PWM converter-inverter system," Industrial Electronics, IEEE Transactions on, Vol. 48, pp. 794-803, 2001.

[16] E. Al-Nabi, W. Bin, N. R. Zargari, and V. Sood, "Input Power Factor Compensation for High-Power CSC Fed PMSM Drive Using d -Axis Stator Current Control," Industrial Electronics, IEEE Transactions on, vol. 59, pp. 752-761, 2012.

[17] D. Jingya, D. D. Xu, and W. Bin, "A Novel Control Scheme for Current-Source-Converter-Based PMSG Wind Energy Conversion Systems," Power Electronics, IEEE Transactions on, Vol. 24, pp. 963-972, 2009.

[18] D. Jovcic, "Offshore wind farm with a series multiterminal CSI HVDC," Electric Power Systems Research, Vol. 78, pp. 747-755, 2008.

[19] M. Popat, B. Wu, and N. R. Zargari, "DC link current control of cascaded current source converter based offshore wind farms," in Electric Machines \& Drives Conference (IEMDC), 2011 IEEE International, 2011, pp. 807-812.

[20] Garce, x, A. s, and M. Molinas, "A Study of Efficiency in a Reduced Matrix Converter for Offshore Wind Farms," Industrial Electronics, IEEE Transactions on, Vol. 59, pp. 184-193, 2012.

[21] S. Mingming, Z. Bo, W. Jiadan, Z. Zhuoran, M. Yiran, and H. Chu, "Design and Practical Implementation of a Novel Variable-Speed Generation System," Industrial Electronics, IEEE Transactions on, Vol. 58, pp. 5032-5040, 2011.

[22] M. Mohr, W. T. Franke, B. Wittig, and F. W. Fuchs, "Converter Systems for Fuel Cells in the Medium Power Range - A Comparative Study," Industrial Electronics, IEEE Transactions on, Vol. 57, pp. 2024-2032, 2010.

[23] B. Wu, High-power converters and AC drives: Wiley, 2006.

[24] J. R. Espinoza and G. Joos, "State variable decoupling and power flow control in PWM current-source rectifiers," Industrial Electronics, IEEE Transactions on, Vol. 45, pp. 78-87, 1998.

[25] G. Hua, X. Dewei, W. Bin, and Y. Geng, "Active Damping for PMSG-Based WECS With DC-Link Current Estimation," Industrial Electronics, IEEE Transactions on, Vol. 58, pp. 1110-1119, 2011.

[26] K. Tan and S. Islam, "Optimum control strategies in energy conversion of PMSG wind turbine system without mechanical sensors," Energy Conversion, IEEE Transactions on, Vol. 19, pp. 392-399, 2004.

[27 Y.Y. Xia, K.H. Ahmed, and B.W. Williams, 'Wind Turbine Power Coefficient Analysis of a New Maximum Power Point Tracking Technique', IEEE Transactions on Industrial Electronics, Volume 60, Issue 3, March 2013, pp. 1122-1132.

[28] B. W. Williams, Power electronics: devices, drivers, applications, and passive components:

http://homepages.eee.strath.ac.uk/ bwilliams/book.htm.

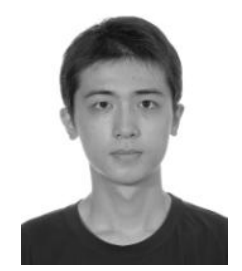

Yuanye Xia received the B.Eng. degree from Zhejiang University, Hangzhou, China, in 2008, and the Ph.D. degree from Strathclyde University, Glasgow, U.K., in 2012. His research interests are digital control of power electronic systems, wind energy conversion system and current source converter.

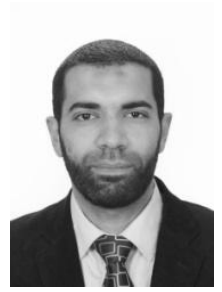

Khaled H. Ahmed received the B.Sc. (first class honours) and M.Sc. degrees from the Faculty of Engineering, Alexandria University, Egypt in 2002 and 2004, respectively. He received the Ph.D. degree in electrical engineering from the Electrical Department, Strathclyde University, Glasgow, UK, 2008. Since 2014, he has been an associate Professor at the Alexandria University, Alexandria, Egypt. He has authored or coauthored more than 70 technical papers in refereed journals and conferences. Dr. Ahmed is an IEEE senior member and a reviewer for the IEEE Transactions and several conferences. His research interests are digital control of power electronic systems, power quality, micro-grids and distributed generation, DC/DC converter, and HVDC.

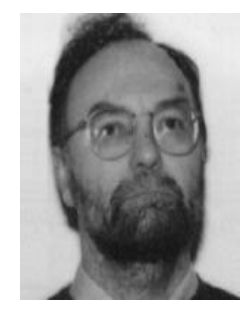

Barry W. Williams received the M.Eng.Sc. degree from the University of Adelaide, Australia, in 1978, and the Ph.D. degree from Cambridge University, Cambridge, U.K., in 1980. After seven years as a Lecturer at Imperial College, University of London, U.K., he was appointed to a Chair of Electrical Engineering at Heriot-Watt University, Edinburgh, U.K, in 1986. He is currently a Professor at Strathclyde University, UK. His teaching covers power electronics (in which he has a free internet text) and drive systems. His research activities include power semiconductor modeling and protection, converter topologies, soft switching techniques, and application of ASICs and microprocessors to industrial electronics. 